\title{
Relationship among Executive Functions, Vocabulary and Reading Skills in School-Aged Children with and without Poor Vocabulary
}

\author{
Jeewon Yoo, Dongsun Yim \\ Department of Communication Disorders, Ewha Womans University, Seoul, Korea
}

Correspondence: Dongsun Yim, PhD Department of Communication Disorders, Ewha Womans University, 52 Ewhayeodae-gil, Seodamun-gu, Seoul 03760, Korea

Tel: $+82-2-3277-6720$

Fax: $+82-2-3277-2122$

E-mail: sunyim@ewha.ac.kr

Received: July 5, 2018

Revised: August 6, 2018

Accepted: August 22, 2018

This work was supported by the Ministry of Education of the Republic of Korea and the National Research Foundation of Korea (No. NRF2016S1A5B5A01021774)
Objectives: We aimed to compare the executive function (EF) skills between children with typical development (TD) and children with poor vocabulary (PV), and to explore how and what kinds of connections exist between the three components of the EF system and language abilities, including vocabulary knowledge and reading ability, in two groups. Methods: Twenty children with TD and 15 children with PV were assessed via tests of working memory, inhibition, and shifting in both verbal and nonverbal modalities, and standardized vocabulary and reading tests were also administered. Results: Comparisons between the two groups revealed that both groups performed comparably on all EF tasks except for the digit n-back task, with the TD group having a higher accuracy than the PV group. Correlational analyses revealed the significant relationships between language abilities (reading and vocabulary knowledge) and verbal working memory as well as between vocabulary knowledge and shifting for the TD group, whereas no relationship between language abilities and EF was found in the PV group. Conclusion: These findings highlight the different relationships between EF and language abilities in two groups, while showing close links between language abilities and EF only for the TD group. This suggests that EF systems may not be efficiently involved in language related abilities in children with PV.

Keywords: Executive function, Vocabulary, Reading, Poor vocabulary
Executive function (EF) is a collection of higher-order cognitive processes that are responsible for purposeful, goal-driven behavior (e.g., Miyake et al., 2000; Stuss \& Alexander, 2000). In confirmatory factor analysis study (Miyake et al., 2000), three EF skills including inhibition, updating and task shifting were proposed as fundamental components of EF. Authors suggested that these three EF skills were independent and also related each other, emphasizing both unity and diversity of EF. According to Diamond (2013), inhibition refers to the ability to restrain attention to ignore irrelevant information, usually measured by a flanker task, Stroop task, go/no-go task, etc. Likewise, updating refers to the ability to monitor and renew upcoming information to incorporate in working memory (WM), measured using the backward digit span task, backward matrix task, reading span task, etc., and shifting refers to the ability to flexibly switch the attention to apply a given rule, measured by the Dimensional Change Card Sorting (DCCS) task, Trail Making Test (TMT), local/global task, etc. Whereas Miyake et al. (2000) suggested a relatively simple integrative model of an EF system with three core-components included, the conceptualization of EF has still not been settled in the field of cognitive research (Fisk \& Sharp, 2004). Thus, many types of EF tasks have been developed and adopted in various studies depending on the research purposes or on participants' characteristics, such as age and language proficiency, which has caused inconsistent and complex data to be in- 
terpreted. Also, MacDonald and Christiansen (2002) raised the question of verbal EF tasks, such as the reading span task measuring WM capacity, maybe not tapping the verbal WM ability. Instead, the verbal EF task may be a one-of-a-kind tapping language skill since the task itself is heavily language dependent. Thus, research accounting for verbal EF as one influential factor in the language abilities can be confounded with common language-dependent variance between the verbal EF tasks, for example, the reading span task, and other language tasks.

Aside from the on-going debate regarding task impurity and inconsistent results found in EF studies, extensive research has been conducted to examine the contribution of EF to the language abilities, such as vocabulary development (Yim, Kim, \& Yang, 2016) and reading ability (Borella \& De Ribaupierre, 2014; Cain, Oakhill, \& Bryant, 2004). In addition, the close link between EF and language abilities, observed not only in the population with typical language development but also in the population with language impairments, such as specific language impairment (SLI) and autism spectrum disorders (Ellis Weismer, Plante, Jones, \& Tomblin, 2005; Joseph, McGrath, \& Tager-Flusberg, 2005), drove many researchers to investigate the underlying mechanism of how $\mathrm{EF}$ and language would interact. Although there is a general consensus about the reciprocal interaction between EF and language skills, it is unclear whether and how each component of EF system would interact with specific language ability in children.

In the present study, we report data examining the connection between language abilities - including vocabulary knowledge and reading skill - and EF in the verbal and nonverbal domain. We examined the association between EF and language abilities in the theoretical framework of EF model suggested by Miyake et al. (2000) so that three components of EF skills were included in this study. Specifically, we adopted the less language dependent verbal WM task, digit $n$-back task, instead of using the reading span task to avoid the common reliance on language-dependent variance as a potential confounding factor between verbal EF tasks and language tasks as best as possible.

\section{EF and Reading}

The close connection between the EF and reading abilities, specifically reading comprehension, has been well established (Borel- la \& De Ribaupierre, 2014; Cain et al., 2004). For instance, Borella and De Ribaupierre (2014) used the reading span task and the matrix task to examine the influence of WM on text comprehension skills in children aged 10-12. They showed that working memory in particular contributed to explaining the variance in text comprehension, confirming the crucial role of WM in reading comprehension. Similarly, Cain et al. (2004) further suggested that working memory accounted for a significant variance in 7- and 8-year-old children's reading comprehension after controlling for individual vocabulary skills and word recognition. These results suggest that WM plays a central part in reading comprehension, enabling readers to process information and hold relevant information to construct a coherent representation of the text's meaning. Many studies examining the contribution of EFs to reading skills have mostly focused on working memory, and inhibition and shifting have received little attention when accounting for reading skills. However, inhibition is also considered to be relevant to reading because inhibition may prevent individuals from misinterpreting ambiguous representations caused by either single words or a text passage (Gernsbacher \& Faust, 1991). Some studies have shown that children with reading difficulties have difficulties suppressing irrelevant information, suggesting that poor comprehension is related to poor cognitive inhibition. For instance, Swanson, Howard, and Saez (2006) reported that children with reading disabilities responded less accurately than their peers with typical language development in a task with random letters and numbers that required participants to suppress responses that would lead to correctly ordered numbers or letters, such as 1, 2, 3, 4 or a, b, c, d. Similarly, shifting, also known as cognitive flexibility is relevant to the reading ability since it allows individuals to simultaneously process phonological and semantic information and to recall multiple mental representations or to adjust reading strategies depending on the reading goal and task difficulty (Nouwens, Groen, \& Verhoeven, 2016). For example, Van der Sluis, De jong, and Van der Leji (2007) investigated the relations between executive functions and reading, arithmetic, and (non)verbal reasoning in children aged 9-12 using eleven EF tasks, such as Stroop, Making Trails, and digit memory. The results showed that shifting was mainly associated with reading and verbal reasoning.

However, all studies examining EF and language abilities did 
not yield consistent results, as we mentioned earlier. Some studies found a significant relationship between EF and reading, as observed in the previous works given above (Borella \& De Ribaupierre, 2014; Cain et al., 2004; Swanson et al., 2006; Van der Sluis et al., 2007), whereas others did not (Chiappe, Hasher, \& Siegel, 2000; St Claire-Thompson \& Gathercole, 2006). For instance, Chiappe et al. (2000) suggested that good and poor decoders have no difference in measures of cognitive inhibition. Similarly, St Claire-Thompson and Gathercole (2006) failed to find the relationship between shifting and children's literacy skills, including reading, writing, and spelling, whereas they found a close relation between two executive factors (updating and inhibition) with achievement in English. These data contrast with results demonstrating significant associations between EF and reading abilities, resulting in unclear results for how the EF system relates to reading.

\section{EF and Vocabulary}

On the other hand, vocabulary knowledge has not been as extensively studied in relation to EF as reading ability (Yang \& Yim, 2018; Yim et al., 2015, 2016). Yang and Yim (2018) recruited 70 Korean children aged from 5 to 6 , and divided them into children with typical development (TD group) and children with vocabulary delay (VD group). Authors examined whether and how EF (WM, inhibition, shifting) and word learning abilities including quick incidental learning (QUIL) and vocabulary knowledge would be related. Children were administered not only Receptive \& Expressive Vocabulary Test (REVT; Kim, Hong, Kim, Jang, \& Lee, 2009) and QUIL tasks for measuring word learning abilities but also a nonword repetition task (NWR), a stop signal task (SST) and a DCCS task for measuring WM, inhibition, and shifting abilities. The general findings were that the TD group outperformed all EF tasks and word learning tasks, and there were the significant correlations between vocabulary knowledge and all of the EF components for the TD group whereas there were significant correlations between vocabulary knowledge and inhibition ability for the VD group. These findings implied the link between EF and vocabulary knowledge not only in the TD group but also partially in the VD group.

There is also evidence showing the possible linkage between EF and vocabulary knowledge (Emerson \& Miyake, 2003; Gathercole,
Frankish, Pickering, \& Peaker, 1999). For example, a considerable body of evidence reported that short-term memory (STM) and vocabulary acquisition are highly correlated (Gathercole et al., 1999). According to the multi-component WM model suggested by Baddeley (2000), WM relies on the function of the phonological loop (PL) and the central executive (CE) in the model. PL refers to the ability to retain the verbal information for a brief period of time, and the task to tap the PL is regarded as measuring the STM capacity. Therefore, it is reasonable to infer that the WM may be related to vocabulary knowledge. While little is known about how the other EF components like inhibition and shifting would be related to vocabulary development, indirect associations have been found between shifting and verbal abilities. Shifting tasks such as DCCS or TMT (Trail Making Test) require children to change their attention to the given target dimension or the targeted sequences. Some studies have demonstrated that inner speech or verbal self-instruction reduces switching costs, indicating that general verbal ability is linked to the EF system, such as shifting (Emerson \& Miyake, 2003), although these findings did not support a direct relation between vocabulary and shifting.

In addition, some studies have demonstrated that EF in general is one of the factors accounting for vocabulary growth (Weiland, Barata, \& Yoshikawa, 2014). For instance, Weiland et al. (2014) examined the associations using a structural equation model between EF and receptive vocabulary in preschoolers. EF skills, including WM (forward digit span, backward digit span), attention shifting (DCCS) and inhibitory cognitive control (pencil tapping) as well as receptive vocabulary skills were measured at the beginning of preschool and at the end of preschool for about 400 preschoolers. The results showed that EF skills at the beginning of preschool significantly predicted receptive vocabulary skills at the end of preschool while receptive vocabulary skills at the beginning of preschool did not predict EF skills at the end of preschool. These results indicate that EF may play an important role in the growth of language skills, supporting the accounts of the neurobiological mechanism or cognitive mechanism that direct the developmental pathway of EF skills supporting language.

Together, it seems there may be a dynamic interplay between EF and reading skills and between EF and vocabulary knowledge during children's language development. Although many studies have 
been conducted to delineate the relationship between EF and vocabulary knowledge as well as between EF and reading skill, most studies have utilized a single EF component task or EF tasks that were mixed in domains. This may result in inconsistent results, and the interpreting of these results is complex. In fact, it is rare to find all three components in the EF system included to explore the role of EF in language development within the same participants. In the current study, a group comparison between children with TD and children with poor vocabulary (PV) is used with three core components tasks of EF to explore whether the connections between EF and reading skill as well as vocabulary knowledge would differ between children with TD and children with PV.

\section{Aims of the Current Study}

Few works have investigated the role of EF-including all three core components and both verbal and nonverbal modalities - in language abilities in Korean school-aged children, and little research has directly examined the critical factors such as the EF system, reading skills and vocabulary knowledge. First, we aimed to compare the EF skills between children with TD and children with PV. Our second aim was to explore how and what kinds of connections would exist between the three components of the EF system and language skills, including vocabulary knowledge and reading ability measured by standardized tests of REVT (Kim et al., 2009) and KISE-BAAT Reading (Korea Institute for Special Education-Basic Academic Achievement Test; Park, Kim, Song, Jung, \& Jung, 2008), in children with PV as well as in children with TD. We chose school-aged children because some research has suggested that EF skills in children before entering elementary school may be unidimensional, and so it may be hard to observe distinct EF factors in language skills (e.g., Barata, 2011). We specifically chose children at early elementary school because during this period of time most of children were obtaining basic literacy skills, which was closely connected to later academic success (Barone, 2003; Snow \& Matthews, 2016) as well as because the distinctive ability in reading (e.g., word recognition) is associated with children with poor reading ability who were at early elementary school rather than from children at higher elementary school (Kim \& Pae, 2012; Van Kleeck, 2007).

\section{METHODS}

\section{Participants}

Twenty children with TD and 15 children with PV participated in this study. Children aged from 7;0 to 9;6 were recruited from areas of Seoul and Chungnam in Korea. All of the children were in 1st to 3rd grade; in the TD group, 6 children were in 1st grade, 12 children were in 2 nd grade, and 2 children were in 3rd grade, whereas in the PV group, 5 children were in 1st grade, 4 children were in 2nd grade, and 6 children were in 3rd grade.

The criteria for the PV group were (1) in the normal range of the nonverbal IQ indexed by the nonverbal subtest of Korean version of Kaufman Assessment Battery for Children (K-ABC; Moon \& Byun, 1997), (2) to have -1.25 SD below the mean score of either receptive or expressive vocabulary (REVT), and (3) not to have previous history of speech or language-related disorders. The criteria for the TD group were (1) in the normal range of the nonverbal IQ indexed by the nonverbal subtest of K-ABC, (2) to have $1 \mathrm{SD}$ above from the mean score of REVT, and (3) not to have any previous history of speech or language related disorder.

All participants completed standardized tests of vocabulary (REVT), non-verbal IQ (K-ABC), and reading (KISE-BAAT). The two groups did not differ in their age and nonverbal IQ; however, the TD group had higher vocabulary scores than the PV group, including both expressive and receptive vocabulary. Also, the TD group had a higher reading score than the PV group. The participants' characteristics were presented in Table 1.

Table 1. Participants' characteristics

\begin{tabular}{lccc}
\hline & TD group (N=20) & PV group (N=15) & $Z$ \\
\hline Age (yr) & $8.23(.70)$ & $8.4(.77)$ & -.94 \\
Non-verbal IO ${ }^{\text {a }}$ & $113.65(9.0)$ & $108.07(10.44)$ & -1.37 \\
REVT (raw score) & & & \\
Receptive vocabulary & $101.25(12.21)$ & $78.87(11.71)$ & $-4.09^{* *}$ \\
$\quad$ Expressive vocabulary & $98.65(11.78)$ & $85.27(10.93)$ & $-3.07^{* *}$ \\
KISE-BAAT reading (RA0) & $110.85(7.88)$ & $102.53(9.47)$ & $-2.19^{*}$ \\
\hline
\end{tabular}

Values are presented as mean $\pm \mathrm{SD}$.

$\mathrm{PV}=$ children with poor vocabulary; $\mathrm{TD}=$ children with typical development; $\mathrm{REVT}=$ Receptive \& Expressive Vocabulary Test (Kim, Hong, Kim, Jang, \& Lee, 2010); KISEBAAT = Korea Institute for Special Education-Basic Academic Achievement Test (Park, Kim, Song, Jung, \& Jung, 2008); RAQ= reading achievement quotient. ${ }^{a}$ Korean-Kaufman Assessment Battery for Children (Moon \& Byun, 1997). ${ }^{*} p<.05,{ }^{* *} p<.01$. 


\section{Task and Procedure}

After completing the standardized tests including REVT, K$\mathrm{ABC}$, and KISE-BAAT-reading, all participants were administered a series of EF tasks including WM tasks (digit n-back task, shape n-back task), inhibition tasks (Stroop task, flanker task), and shifting tasks (TMT, DCCS task). We used SuperLab 5 software (Cedrus Corporation, San Pedro, CA, USA) to present all of the EF tasks except for TMT, which was a paper and pencil based test. The order of presentation of EF tasks was fixed in three different ways to avoid the order effect, so that some children were administered the WM task first, some children were administered the inhibition task first, etc. Two or three sessions, with each session lasting 30-40 minutes, were taken to complete the standardized tests and EF tasks. One of the authors and two trained graduate students administered all tasks.

\section{Reading ability}

KISE-BAAT-reading was used to measure each child's reading ability. It is a well-established norm-referenced reading test that assesses the reading ability level of children aged 5;0 through 14;11 in Korea. KISE-BAAT-reading comprises three subtests: visual discrimination, phonemic decoding, and reading comprehension. The 'visual discrimination' was administered to measure a child's letter and word awareness, which is a primary factor underlying early reading achievement. The 'phonemic decoding' subtest was used as a measure of phonemic awareness. The 'reading comprehension' subtest assesses the child's ability to understand words, sentences and short passages. Items were scored as either correct (1 point) or incorrect ( 0 point) for each task. The correct raw score for each subtest was collected, and converted to scaled scores and RAQ (reading achievement quotient). RAQ score was used for final analyses in the current study following the previous study (Kim \& Pae, 2013).

\section{Working memory}

The n-back task, which is a classical updating task, was used to measure the WM ability (Jaeggi, Buschkuehl, Perrig, \& Meier, 2010). We utilized the same n-back paradigm used in previous studies with children aged from 8-10 (Gangopadhyay, Davidson, Ellis Weismer, \& Kaushanskyaya, 2016). We used the digit n-back task to measure verbal WM and the shape n-back task to measure visual WM. For the digit n-back task, 9 digits from 1 to 9 were used; while 9 shapes, which were unable to be labeled, were used for the visual n-back task (Vanderplas \& Garvin, 1959). In both WM tasks, children were asked to recall the target stimulus that was located in positions before in the sequence. Children responded to each stimulus by pressing a red button if the presented stimulus was a target and a blue button if the presented stimulus was a non-target. Each trial was coded as ' 1 ' if children responded correctly and was coded as '0' if children responded incorrectly or did not respond. The overall mean of the proportion of accuracy across three conditions in each WM task was obtained and was used for the analyses.

\section{Inhibition}

Inhibition was measured using the Stroop task and the flanker task. These two tasks have been frequently used to measure inhibitory control (Davelaar \& Stevens, 2009; MacLeod, 1992). We used the same inhibition tasks utilized in previous studies with children aged 7-8 (Kong \& Yoo, 2017). In the flanker task, three conditions were constructed using fish stimuli. For the congruent condition, all five fish, including both the flanker fish and a middle fish, face the same direction. For the incongruent condition, the flanker fish faced the opposite direction compared to the middle fish. For the neutral condition, the flanker stimuli were squares. In this task, children were asked to focus on the middle fish while ignoring the flanker fish (surrounding fish), press a red button if the middle fish faced the right, and press a blue button if the middle fish faced the left as quickly and accurately as possible.

Similar task parameters were used to construct the Stroop task. In this task, for the congruent condition, the color and the word were matched (i.e., the Korean word for 'red' was presented in a red color). For the incongruent condition, the color and the word did not match (i.e., the Korean word for 'red' was presented in blue color). For the neutral condition, instead of a word, a meaningless symbol 'XXX' with a random color was used. In this task, children were asked to press a red button if the color and the word were matched and to press a blue button as fast and accurately as possible otherwise.

Each trial was coded as ' 1 ' if the children responded correctly 
and was coded as ' 0 ' if the children responded incorrectly or did not respond. The accuracy and reaction time (RT) of each condition were collected for each task. Then, the inhibition effect was obtained by subtracting the RTs in the congruent condition from the RTs in the incongruent condition. For the analyses, the inhibition indexes of each inhibition task were used.

\section{Shifting}

To measure the shifting ability, the TMT task and the DCCS task were used. The two tasks have been frequently used to measure the mental flexibility and attentional shifting (Gray, 2006; Zelazo, Frye, \& Rapus, 1996). The TMT task was modified based on a subtest of the Delis-Kaplan Executive Function System (DKEFS; Delis, Kaplan, \& Kramer, 2001) with the English alphabet being replaced by the Korean alphabet (e.g., /ga/ for A, /na/ for B, etc.). The usage of a modified TMT was common in previous studies (e.g., Jung, 2009; Kim et al., 2011). In this task, three conditions were presented in the order of a number condition (1-14), a letter condition (14 Korean letters), and a mixed condition (14 numbers and 14 Korean letters mixed). The children were asked to draw a line to connect each encircled number or encircled letter that had been randomly presented on a sheet of paper, according to their order on a number or a letter condition. For the mixed condition, the children were asked to draw a line by alternating between the numbers and letters (i.e., 1-/ga/-2-/na/-3-/da/). In this task, the children were asked to complete each condition as quickly and accurately as possible, and when they made an error, the children were asked to return the encircled letter or number where the error had been made and to continue the task. The RTs for each condition were measured from when children started the task to when children completed the task. We included the period of children making errors and going back to a previous position. The RTs of each condition when children completed the task were obtained, and the RT of a mixed condition was used for the analysis.

The DCCS task was constructed based on the task used in the National Institutes of Health Toolbox Cognition Battery (http:// www.nihtoolbox.org) for people aged 7-17 years. For the DCCS task, three conditions including pre-condition (shape), post-condition (color), and mixed condition (mixed shape and color), were constructed. The participants were asked to identify the target pictures by both dimensions and press the right or left button as quickly and accurately as possible to choose the correct target picture between them. For each condition, the examiners reminded the participants of the name of the games, and no feedback was provided during the tasks. Each trial was coded as ' 1 ' if children responded correctly and as '0' if children responded incorrectly or did not respond. The accuracies and RTs of each condition were collected for each task. The RT of a mixed condition of the task was used for the analyses.

We considered the shape n-back task, the flanker task, and the DCCS task as the less language-dependent tasks. Nonverbal EF tasks - excluding the digit n-back task, the Stroop task, and the TMT task that we considered as verbal EF tasks - require participants to respond to the picture-based visual stimuli (i.e., shapes, fish, rabbit, ship, ball, truck) even though the instructions are given to participants verbally. In contrast, the verbal EF tasks require participants to remember, decode or monitor phonological/semantic information in order to complete the task.

\section{Analyses}

First, we ran a Mann-Whitney $U$-test to compare the differences on the performances of the EF tasks between the TD group and the PV group. Second, the Spearman correlational analyses were conducted between the reading score and the performances of the EF tasks, and between the vocabulary score and the performance of the EF tasks within each group to examine whether the relationships between language abilities including reading skills and vocabulary knowledge and EF would differ between the two groups.

\section{RESULTS}

\section{EF Performance between Two Groups}

The comparisons of two groups on EF tasks revealed that there was no difference in the EF performance between the TD group and the PV group, except on the digit n-back task, with the TD group having a higher accuracy than the PV group $(U=89.5, p<.05)$. Although two groups performed comparably on the inhibition tasks and shifting tasks for which the abilities were captured based on children's RTs, the overall accuracies of the flanker task $\left(\mathrm{M}_{\mathrm{TDgroup}}=\right.$ $.98, \mathrm{SE}=.004$ vs. $\left.\mathrm{M}_{\text {PVgroup }}=.96, \mathrm{SE}=.01\right)$, the Stroop task $\left(\mathrm{M}_{\mathrm{TDgroup}}=\right.$ 
$\left..94, \mathrm{SE}=.009 \mathrm{vs} . \mathrm{M}_{\mathrm{PVgroup}}=.87, \mathrm{SE}=.04\right)$, and the DCCS task $\left(\mathrm{M}_{\mathrm{TDgroup}}\right.$ $=.93, \mathrm{SE}=.02$ vs. $\left.\mathrm{M}_{\mathrm{PVgroup}}=.86, \mathrm{SE}=.03\right)$ were compared between the two groups to examine whether there was any difference in the accuracy to perform the tasks. The results showed that both groups performed comparably in the accuracies of the flanker task $(U=108.5$, $p=.14)$, the Stroop task $(U=112.5, p=.18)$, and the DCCS task ( $U=96, p=.6$ ). There was a trend of the TD group performing better than the PV group in the DCCS task although it failed to reach the level of statistical significance. The visual representa-

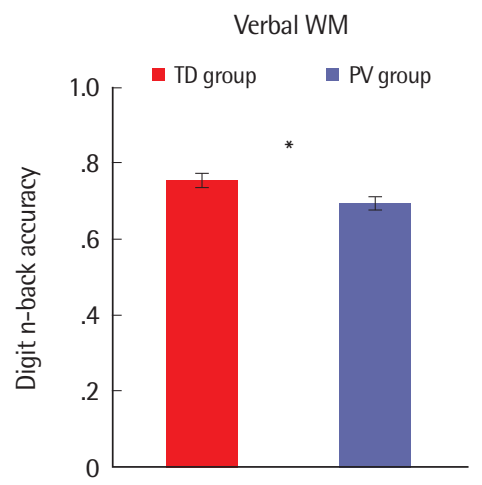

Verbal inhibition effect

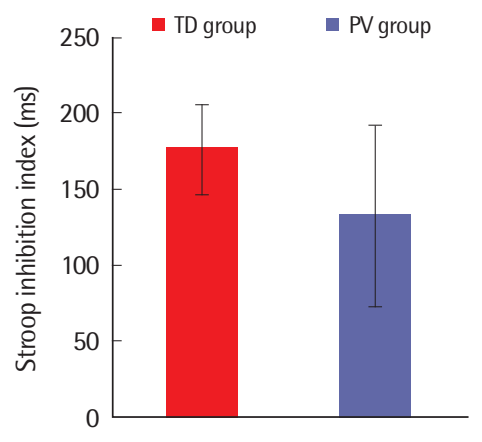

Verbal shifting

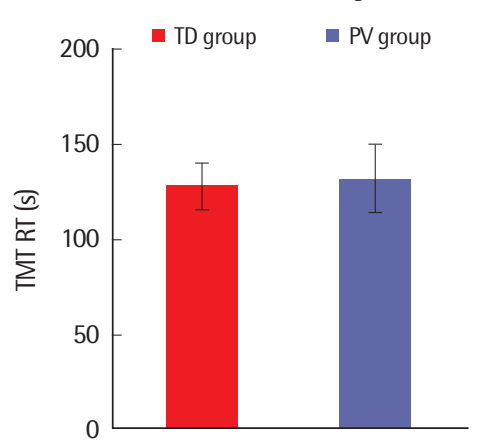

tions of the EF performances between the two groups can be found in Figure 1.

\section{Correlational Analyses between EF and Language Abilities}

For the TD group, the correlational analyses revealed a positive relationship between the reading skill and verbal WM indexed by digit $n$-back task $(r=.62, p<.01)$ as well as between the expressive vocabulary knowledge and the verbal WM $(r=.48, p<.05)$. Simi-
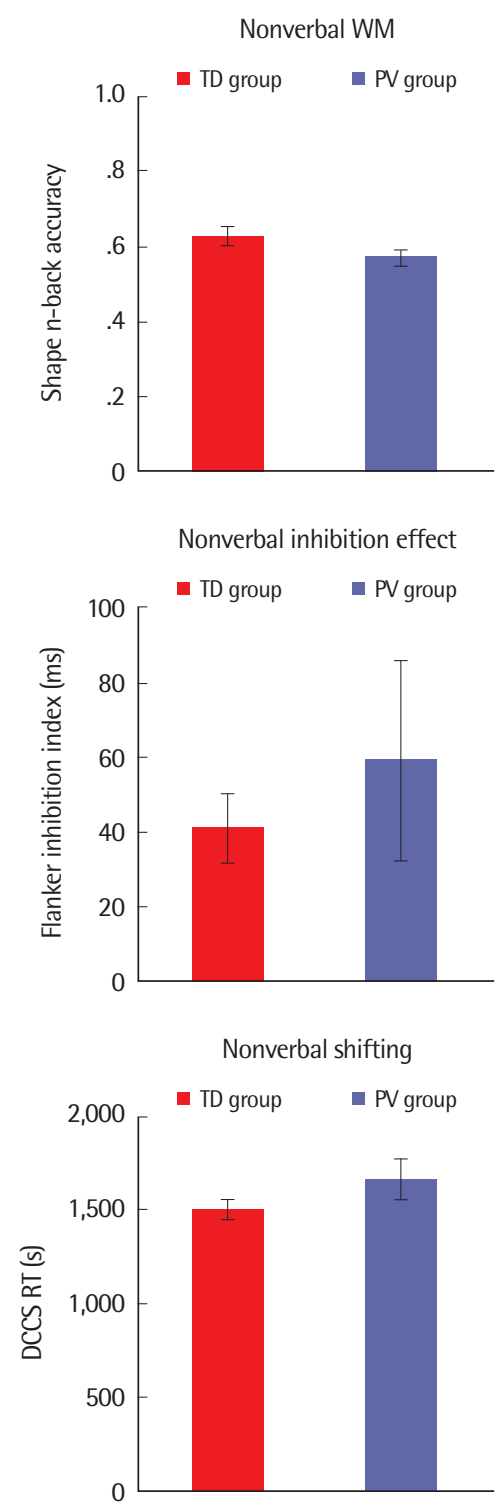

Figure 1. Performances on executive function tasks between the TD group and the PV group. Error bar represents standard error. PV=children with poor vocabulary; TD=children with typical development; TMT=trail making test; DCCS=dimensional change card sorting; $\mathrm{RT}=$ reaction time.

${ }^{*} p<.05$. 
Table 2. Correlational matrix between executive function and language abilities (vocabulary and reading) within each group

\begin{tabular}{lccc}
\hline & $\begin{array}{c}\text { REVT-receptive } \\
\text { vocabulary }\end{array}$ & $\begin{array}{c}\text { REVT-expressive } \\
\text { vocabulary }\end{array}$ & $\begin{array}{c}\text { KISE-BAAT reading } \\
\text { (RAO) }\end{array}$ \\
\hline TD group & & & \\
$\quad$ Digit n-back & .26 & $.48^{*}$ & $.62^{* *}$ \\
Shape n-back & .20 & .18 & .33 \\
Flanker & .14 & .12 & .05 \\
Stroop & -.25 & .02 & -.20 \\
DCCS RT & $-.53^{*}$ & $-.62^{* *}$ & -.12 \\
TMT & $-.71^{* *}$ & $-.58^{* *}$ & -.22 \\
PV group & & & \\
Digit n-back & -.05 & -.41 & .32 \\
Shape n-back & -.49 & -.02 & .08 \\
Flanker & .44 & -.27 & .11 \\
Stroop & -.06 & -.02 & .14 \\
DCCS RT & -.33 & -.24 & .19 \\
TMT & -.47 & .04 & .13 \\
\hline
\end{tabular}

Values are presented as $r$.

$\mathrm{PV}=$ children with poor vocabulary; $\mathrm{TD}=$ children with typical development; $\mathrm{TMT}=$ trail making test; $\mathrm{DCCS}=$ dimensional change card sorting; $\mathrm{RT}$ = reaction time; $\mathrm{REVT}=$ Receptive \& Expressive Vocabulary Test (Kim, Hong, Kim, Jang, \& Lee, 2010); KISEBAAT =Korea Institute for Special Education-Basic Academic Achievement Test (Park, Kim, Song, Jung, \& Jung, 2008); RAQ = reading achievement quotient. ${ }^{*} p<.05,{ }^{* *} p<.01$.

larly, negative relationships between the vocabulary knowledge including both receptive and expressive vocabulary and shifting indexed by both TMT $\left(r_{\text {receptive }}=-.71, p<.01\right.$ vs. $\left.r_{\text {expressive }}=-.58, p<.01\right)$ and DCCS tasks $\left(r_{\text {receptive }}=-.53, p<.05\right.$ vs. $\left.r_{\text {expressive }}=-.62, p<.01\right)$ were observed only for the TD group. However, no such relationship was observed between the vocabulary knowledge and EF abilities or between the reading skill and the EF abilities for the PV group (see Table 2 for the correlational matrixes within each group).

\section{DISCUSSION AND CONCLUSION}

In the present study, we investigated whether the EF abilities indexed by both verbal and nonverbal EF tasks would separate the TD group form the PV group, and we further examined whether the relationships between the EF and language abilities, including vocabulary knowledge and reading skills within each group, would differ between the TD group and the PV group. We found that the verbal WM component of EF differed between two groups, with the TD group having better WM ability than the PV group. In addition, there was a positive correlation between verbal WM ability and reading skill, showing that children with higher verbal WM ability had better reading skill in the TD group. Also, there were negative correlations between the shifting ability and vocabulary knowledge and the positive correlation between the receptive vocabulary and the reading skills, showing that children with better shifting abilities or WM ability had higher vocabulary knowledge in the TD group. In contrast, in the PV group, there was no correlation between the EF and any language abilities.

The finding of a higher verbal WM skill for the TD group compared to the PV group was in line with prior evidence showing a link between STM and vocabulary acquisition (Gathercole et al., 1999; Weiland et al., 2014). According to multi-components WM model (Baddeley, 2000), verbal WM relies on the function of the $\mathrm{PL}$ and the CE. The PL has been known as an influential factor in word learning and vocabulary development (Gathercole et al., 1999). While the PL is responsible for retaining verbal information during a brief period and thus appears to be a clear link between PL and word knowledge, the role of WM involving both PL and CE in vocabulary learning/development is plausible, as has been documented in previous studies (Ellis, 1996). Therefore, it seems that the inefficient WM system in the verbal domain in PV group compared to the TD group may lead to a lagged vocabulary development or the opposite direction would be also possible in the present study.

The finding of a higher verbal WM ability in the TD group than in the PV group can also be linked to the positive connections between verbal WM and reading skill observed only in the TD group, but not in the PV group who underperformed on the standardized tests of reading and vocabulary compared to the TD group. In reading comprehension research, it is a robust finding for the WM and reading skill to be closely connected (Borella \& De Ribaupierre, 2014; Cain et al., 2004). In particular, a large number of studies demonstrated that reading comprehension was mediated by the WM system (Cain et al., 2004; Nouwens et al., 2016). The frequently-used account for this connection was that reading activity mirrors the WM functions. That is, a reader must hold/remember previously read information to integrate what he/she has to read next to fully comprehend the content during reading, and this reading activity is very similar to the WM function of holding the information for a short period of time while processing a second- 
ary cognitive activity. Even though the standardized reading test used in the present study was composed of three subtests, including visual discrimination, phonemic decoding, and reading comprehension, only the reading comprehension subtest score was obtained by five different comprehension tasks. That is, a large portion of KISE-BAAT was formed by the reading comprehension skill. When we ran follow-up correlational analyses between three sub-tests in KISE-BAAT and verbal WM, only the relationship between the reading comprehension subtest and verbal WM reached statistical significance $(r=.64, p<.01)$. In that sense, our findings of the positive association between verbal WM and performance on the standardized reading test is likely to support previous findings of the WM influencing reading comprehension performance (Borella \& De Ribaupierre, 2014; Cain et al., 2004). In a similar vein, the association between vocabulary knowledge and verbal WM observed in the TD group aligned with the prior study (Yim et al., 2016). As Baddeley's WM model proposed, the PL, which is a part of function of WM, is tightly linked to the vocabulary acquisition (Gathercole et al., 1999). The STM task, tapping the PL, is known to measure the ability of storing phonological information for brief period, and it is reported to be a crucial ability for acquiring new words. Therefore, it is not strange that WM, which carries the variance of STM, is linked to vocabulary knowledge.

However, we found a meaningful relationship between language abilities (reading \& vocabulary) and WM only in the verbal domain, not in the nonverbal domain. While we do not deny the possibility that the common reliance on the language-related factor between the verbal WM task and language-related task (reading \& vocabulary tasks) may drive this finding, the point should be made that the digit n-back task used to measure the verbal WM skill in the current study is less language-dependent compared to other verbal WM tasks, like the reading span task that has been widely used to measure verbal WM skills in other studies (Yoo \& Kaushanskaya, 2012). That is, processing digits is highly automatic and retaining or retrieving digit information may not depend much on language processing, as the reading span task does, so we suggest that our findings of the links between verbal WM and performances on the language tasks may reflect the verbal WM component in EF related to language abilities, which is not confounded by the common language factor between two tasks.
We did not find any difference on performance of other EF tasks such as inhibition and shifting between two groups. These findings were inconsistent with the prior study reporting the general EF deficits in children with vocabulary delay (Yang \& Yim, 2018) while they were consistent with some studies reporting similar findings on EF performance between the TD group and language delayed group as observed in current study (Arbel \& Donchin, 2014; Marton et al., 2014). One of possible factors leading to these contrasting findings may be due to children's developmental change in the EF system. The degree of EF development is a crucial factor that might influence on the relationship between EF and language abilities since EF is known to develop from the age of 3 until adulthood and variability in development of EF sub-components exists (Zelazo et al., 1996; Zelazo \& Müller, 2002). For instance, children at the age of 3 are well known to fail to flexibly change the cognitive rule depending on the specific goal in the DCCS task while relatively older children can perform this task with ease (Zelazo et al., 1996).

Given that children aged 5-6 were recruited in Yang and Yim's study whereas relatively older children (aged 7-9) were recruited in the current study, it would be possible that the EF tasks used in this study might not be difficult enough to tap the EF system including inhibition and shifting for children in the present study, failing to reach the significant difference even though the tasks used here were suggested as the age appropriate ones. Alternatively, including the ages of 7-9 may cause the comparable results between two groups due to the larger variability within group (as shown in performance of inhibition task in this study).

In addition, we did not find any association between other EF abilities, inhibition and shifting, and reading skill in the TD group. While ours failure to find the link between inhibition or shifting and reading skill were consistent with some previous findings (St ClaireThompson \& Gathercole, 2006), this finding contrasted with other studies that reported a close link between inhibition or shifting and reading skills (Van der Sluis et al., 2007). A possible explanation for this would be due to methodological issues. That is, we adopted EF tasks measuring all three components, including both verbal and nonverbal domains, especially for WM and inhibition. To do so, we only used one task for each domain, and this single EF task used in this study may not yield a sufficiently robust con- 
nection with reading skill. Alternatively, it is possible for the taskspecific effect yielding only WM, not inhibition or shifting, to be related with reading skill. The inhibition and shifting tasks impose speed on performance, with both tasks requiring children to respond as quickly and accurately as possible. Although we collected the accuracies along with RTs in each task, the inhibition effect and shifting abilities were calculated based on the RTs of the tasks. Since the standardized reading test used in this study does not require the performance to be rapid, the reading skill indexed by the standardized test may be far from the time demand where inhibition and shifting tasks impose. Including reading tasks such as the reading fluency task and including more EF tasks in each domain may provide a clearer picture of these issues in a future study.

One important finding was that connections between shifting and vocabulary knowledge were observed in the TD group given that shifting is the least studied EF component in relation with language abilities. TMT requires children to draw a line by alternating between letters and numbers, and the DCCS task requires children to choose correct target depending on the specific dimension that are given. To successfully complete these tasks, children need to flexibly shift their attention between two different targets of information or two dimensions while correctly keeping track of the sequence of numbers and letters or of the dimension. Previous research suggested that general verbal abilities, such as self-verbalization, may have helped to perform the shifting tasks (Baddeley, Chincotta, \& Adlam, 2001). In this study, in fact, while children performed the TMT, many of them used self-guided verbal cues to remind themselves to keep track of what they needed to do next whereas the experimenter reminded children of what dimension was targeted for the DCCS task. It seems that children using this verbal cue may be performing well on shifting tasks, and using a verbal strategy may reflect higher verbal skills which may be linked to general verbal ability, including vocabulary knowledge. Since this is our speculation, further studies need to examine the specific relationship among shifting, verbal strategy, and vocabulary knowledge.

The notable findings were that there was no relationship between EF and either reading ability or vocabulary knowledge in the PV group. Whereas prior studies have examined the relationship be- tween $\mathrm{EF}$ and various language abilities recruiting population with various language disorders in relation with EF system, it is rare to find studies examining a population with PV. Thus, relatively little has been known of the profile of the school-aged children with PV regarding the EF system and language abilities. In the current study, the PV group clearly showed a different relationship between the EF and language abilities compared to the TD group. The TD group not only outperformed the PV group in both standardized tests of reading and vocabulary and had a higher verbal WM skill, but also showed close associations between WM and reading skill and between WM and inhibition and vocabulary knowledge. It appears that the reciprocal interaction between language abilities (vocabulary knowledge and reading skill) and the EF system (WM and shifting) may be efficiently operating in the TD group, but not in the PV group. It seems that the relatively lower language abilities did not yield any connection with any of EF components for the PV group. These findings indicate that EF systems may not be efficiently involved in language-related abilities in the PV group.

The findings in the current study support the unity and diversity of the EF model. As Miyake et al. (2000) suggested, three EF components were related, but also separable. In this study, all of the EF components were not linked to the language abilities in a same way. Instead, each EF component was linked to the specific language abilities such that WM was connected to reading ability while both WM and shifting were connected to expressive vocabulary. These findings suggest that EF skills may not be uniformly related to language abilities, supporting Miyake's EF model.

The current study has clinical implications in that it demonstrated that the PV group had a lower verbal WM system than the TD group, and vocabulary knowledge is linked to the EF (WM and shifting) system only in the TD group. If the poor vocabulary knowledge is responsible for the low EF or the low EF is causing the poor vocabulary knowledge even though the direction was not tested in the current study, the EF task may be utilized to discriminate younger children who may be at risk of language impairment from early on as a supplementary tool along with standardized language tests. For instance, the validity of the shifting task, such as the DCCS task, is well established for younger children from age of 3 (Zelazo et al., 2003), and this EF task may be used with 
standardized vocabulary test to accurately distinguish the late talkers from children with typical development at the earliest possible age. An accurate diagnosis may make it possible for children to receive intervention at the appropriate time. To do so, a future study should include a wider age range to investigate the connection between EF and vocabulary knowledge as a follow-up.

In summary, the current study investigated the relationship between EF and two language abilities, vocabulary knowledge and reading skill. A group comparison dividing school-aged children into the TD group and the PV group revealed higher language abilities including vocabulary knowledge and reading skill in the TD group than in the PV group. The higher language abilities were linked with EF abilities, especially with WM and shifting in the TD group, but these linkages were not available in the PV group. These findings suggest the efficient interplay between EF skills and language abilities may be limited to the PV group compared to the PV group.

However, caution should be taken in interpreting these findings because the current study has some limitations, including the relatively small and unbalanced sample size between the two groups. Also, as mentioned earlier, the EF tasks used in the current study may have been too easy for school-aged children to sensitively distinguish the EF ability between two language groups. To include more age-appropriate EF tasks along with a larger sample size may lead to more robust findings relating EF and language skills in future studies. Finally, we only used one of each domain in each EF component task, and as mentioned before, this may not be sufficient or sensitive enough to tap each EF component. Therefore, future studies need to include more than one EF component task in each domain to observe more reliable results.

\section{REFERENCES}

Arbel, Y., \& Donchin, E. (2014). Error and feedback processing by children with specific language impairment: an ERP study. Biological Psychology, 99, 83-91.

Baddeley, A. (2000). The episodic buffer: a new component of working memory? Trends in Cognitive Sciences, 4, 417-423.

Baddeley, A., Chincotta, D., \& Adlam, A. (2001). Working memory and the control of action: evidence from task switching. Journal of Experimental
Psychology: General, 130, 641-651.

Barata, M. C. (2011). Executive function skills in chilean preschool children. Cambridge, MA: Harvard University.

Barone, D. (2003). Second grade is important: literacy instruction and learning of young children in a high-poverty school. Journal of Literacy Research, 35, 965-1018.

Borella, E., \& De Ribaupierre, A. (2014). The role of working memory, inhibition, and processing speed in text comprehension in children. Learning and Individual Differences, 34, 86-92.

Cain, K., Oakhill, J., \& Bryant, P. (2004). Children's reading comprehension ability: concurrent prediction by working memory, verbal ability, and component skills. Journal of Educational Psychology, 96, 31-42.

Chiappe, P., Siegel, L. S., \& Hasher, L. (2000). Working memory, inhibitory control, and reading disability. Memory \& Cognition, 28, 8-17.

Davelaar, E. J., \& Stevens, J. (2009). Sequential dependencies in the Eriksen flanker task: a direct comparison of two competing accounts. Psychonomic Bulletin \& Review, 16, 121-126.

Delis, D. C., Kaplan, E., \& Kramer, J. H. (2001). Delis-Kaplan executive function system: examiners manual. San Antonio, TX: Psychological Corporation.

Diamond, A. (2013). Executive functions. Annual Review of Psychology, 64, 135-168.

Ellis, N. C. (1996). Working memory in the acquisition of vocabulary and syntax: putting language in good order. The Quarterly Journal of Experimental Psychology Section A, 49, 234-250.

Ellis Weismer, S., Plante, E., Jones, M., \& Tomblin, J. B. (2005). A functional magnetic resonance imaging investigation of verbal working memory in adolescents with specific language impairment. Journal of Speech, Language, and Hearing Research, 48, 405-425.

Emerson, M. J., \& Miyake, A. (2003). The role of inner speech in task switching: a dual-task investigation. Journal of Memory and Language, 48, 148168.

Fisk, J. E., \& Sharp, C. A. (2004). Age-related impairment in executive functioning: updating, inhibition, shifting, and access. Journal of Clinical and Experimental Neuropsychology, 26, 874-890.

Gangopadhyay, I., Davidson, M. M., Ellis Weismer, S., \& Kaushanskaya, M. (2016). The role of nonverbal working memory in morphosyntactic processing by school-aged monolingual and bilingual children. Journal of $E x$ perimental Child Psychology, 142, 171-194.

Gathercole, S. E., Frankish, C. R., Pickering, S. J., \& Peaker, S. (1999). Phono- 
tactic influences on short-term memory. Journal of Experimental Psychology: Learning, Memory, and Cognition, 25, 84-95.

Gernsbacher, M. A., \& Faust, M. E. (1991). The mechanism of suppression: a component of general comprehension skill. Journal of Experimental Psychology: Learning, Memory, and Cognition, 17, 245-262.

Gray, R. (2006). Comprehensive Trail Making Test. Journal of Psychoeducational Assessment, 24, 88-91.

Jaeggi, S. M., Buschkuehl, M., Perrig, W. J., \& Meier, B. (2010). The concurrent validity of the N-back task as a working memory measure. Memory, $18,394-412$.

Joseph, R. M., McGrath, L. M., \& Tager-Flusberg, H. (2005). Executive dysfunction and its relation to language ability in verbal school-age children with autism. Developmental Neuropsychology, 27, 361-378.

Jung, E. (2004). Characteristics of executive function deficits in children with attention deficit-hyperactivity disorder (Doctoral dissertation). Ewha Womans University, Seoul, Korea.

Kim, H. J., Baek, M. J., Chang, Y., Jang, I. M., Ryu, H. J., \& Kim, M. (2011). Comparison between the original version of trail making test with two Korean-trail making tests. Dementia and Neurocognitive Disorders, 10, 95101.

Kim, M., \& Pae, S. (2012). Reading skills and phonological processing abilities of Korean elementary school children with/without poor reading. Korean Journal of Communication \& Disorders, 17, 565-581.

Kim, M., \& Pae, S. (2013). Listening and reading comprehension skills of Korean elementary school children with reading difficulties. Communication Sciences \& Disorders, 18, 392-401.

Kim, Y. T., Hong, G. H., Kim, K. H., Jang, H. S., \& Lee, J. Y. (2009). Receptive \& expressive vocabulary test (REVT). Seoul: Seoul Community Rehabilitation Center.

Kong, E. J., \& Yoo, J. (2017). Speech processing strategy and executive function: Korean children's stop perception. Phonetics and Speech Sciences, 9, 57-65.

MacDonald, M. C., \& Christiansen, M. H. (2002). Reassessing working memory: comment on Just and Carpenter (1992) and Waters and Caplan (1996). Psychological Review, 109, 35-54.

MacLeod, C. M. (1992). The Stroop task: the "gold standard" of attentional measures. Journal of Experimental Psychology: General, 121, 12-14.

Marton, K., Campanelli, L., Eichorn, N., Scheuer, J., \& Yoon, J. (2014). Information processing and proactive interference in children with and without specific language impairment. Journal of Speech, Language, and Hearing
Research, 57, 106-119.

Miyake, A., Friedman, N. P., Emerson, M. J., Witzki, A. H., Howerter, A., \& Wager, T. D. (2000). The unity and diversity of executive functions and their contributions to complex "frontal lobe" tasks: a latent variable analysis. Cognitive Psychology, 41, 49-100.

Moon, S. B., \& Byun, C. (1997). K-ABC (Korean Kaufman Assessment Battery for Children). Seoul: Hakjisa.

Nouwens, S., Groen, M. A., \& Verhoeven, L. (2016). How storage and executive functions contribute to children's reading comprehension. Learning and Individual Differences, 47, 96-102.

Park, G., Kim, G., Song, Y., Jung, D., \& Jung, I. (2008). Korea Institute for Special Education-Basic Academic Achievement Test (KISE-BAAT). Ansan: Korea Institute for Special Education.

Snow, C. E., \& Matthews, T. J. (2016). Reading and language in the early grades. The Future of Children, 26, 57-74.

St Clair-Thompson, H. L., \& Gathercole, S. E. (2006). Executive functions and achievements in school: shifting, updating, inhibition, and working memory. The Quarterly Journal of Experimental Psychology, 59, 745-759.

Stuss, D. T., \& Alexander, M. P. (2000). Executive functions and the frontal lobes: a conceptual view. Psychological Research, 63, 289-298.

Swanson, H. L., Howard, C. B., \& Saez, L. (2006). Do different components of working memory underlie different subgroups of reading disabilities? Journal of Learning Disabilities, 39, 252-269.

Van der Sluis, S., De Jong, P. F., \& Van der Leij, A. (2007). Executive functioning in children, and its relations with reasoning, reading, and arithmetic. Intelligence, 35, 427-449.

Van Kleeck, A. (2007). SLPs' foundational role in reading comprehension: a response to Alan Kamhi. The ASHA Leader, 12, 32-33.

Vanderplas, J. M., \& Garvin, E. A. (1959). Complexity, association value, and practice as factors in shape recognition following paired-associates training. Journal of Experimental Psychology, 57, 155-163.

Weiland, C., Barata, M. C., \& Yoshikawa, H. (2014). The co-occurring development of executive function skills and receptive vocabulary in preschoolaged children: a look at the direction of the developmental pathways. Infant and Child Development, 23, 4-21.

Yang, Y., \& Yim, D. (2018). The role of executive function for vocabulary acquisition and word learning in preschool-age children with and without vocabulary delay. Communication Sciences \& Disorders, 23, 43-59.

Yim, D., Kim, S. Y., \& Yang, Y. (2015). Factor analysis of working memory tasks based on information processing characteristics: predictive factors of 
receptive vocabulary and quick incidental learning in children with typically developing and receptive vocabulary delay. Communication Sciences \& Disorders, 20, 304-318.

Yim, D., Kim, Y. T., \& Yang, Y. (2016). Exploring the utility of verbal and visuospatial working memory for identifying children with language impairment. Communication Sciences \& Disorders, 21, 193-205.

Yoo, J., \& Kaushanskaya, M. (2012). Phonological memory in bilinguals and monolinguals. Memory \& Cognition, 40, 1314-1330.

Zelazo, P. D., \& Müller, U. (2002). Executive function in typical and atypical development. In U. Goswami (Ed.), Handbook of childhood cognitive development (pp. 445-469). Oxford: Blackwell.

Zelazo, P. D., Frye, D., \& Rapus, T. (1996). An age-related dissociation between knowing rules and using them. Cognitive Development, 11, 37-63.

Zelazo, P. D., Müller, U., Frye, D., Marcovitch, S., Argitis, G., Boseovski, J., ... \& Carlson, S. M. (2003). The development of executive function in early childhood. Monographs of the Society for Research in Child Development, 68, i-151. 


\section{국문초록}

\section{학령기 어휘취약아동 및 또래 아동의 집행기능과 어휘 및 읽기능력과의 관계}

\section{유지원 · 임동선}

이화여자대학교 언어병리학과

배경 및 목적: 다양한 언어장애 집단의 집행기능과 언어능력과의 관계는 잘 알려져 있으나, 어휘지체 아동의 집행기능과 언어능력과의 관계에 관한 연구는 찾아보기 힘들다. 본 연구에서는 학령기 일반아동과 어휘취약 아동의 집행기능을 비교하고 집행기능의 3 가지 구 성요소와 읽기 및 어휘를 포함한 언어능력과의 연결관계를 살펴보았다. 방법: 본 연구는 7-9세의 어휘취약 아동(15명)과 일반아동(20 명)을 대상으로 작업기억 억제능력 전환능력을 포함한 언어적/비언어적 집행기능 과제를 실시하고, 규준화된 어휘와 읽기 과제를 시행 하였다. 결과: 일반아동은 digit n-back 과제에서 어휘취약 아동보다 더 높은 정확도를 보였으며 나머지 집행기능 과제에서는 두 그룹이 비슷한 수행능력을 보였다. 일반아동은 언어적 작업기억과 어휘 및 읽기능력 사이에 그리고 전환능력과 어휘 사이에 유의미한 상관관 계가 관찰된 반면, 어휘지체 아동들에게서는 이러한 관계가 관찰되지 않았다. 논의 및 결론: 이 결과는 두 그룹 사이에 집행기능과 언 어능력 사이에 다른 상관관계를 보여준다. 즉, 일반아동의 경우에만 집행기능과 어휘 및 읽기와 같은 언어능력 사이에 긴밀한 연결관계 를 보여주며, 어휘취약 아동의 경우 언어가 관련된 능력에 집행기능이 효과적으로 작동되지 않음을 시사한다.

핵심어: 집행기능, 어휘, 읽기, 어휘취약

본 논문은 대한민국 교육부와 한국연구재단의 지원을 받아수행된 연구임(No. NRF-2016S1A5B5A01021774). 